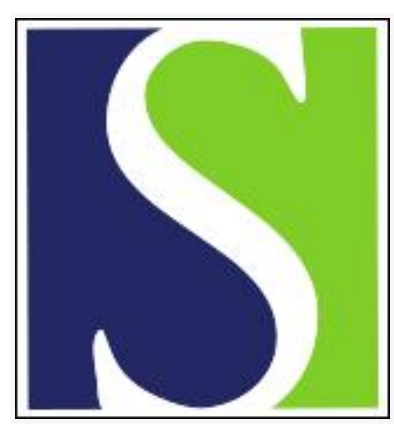

Scand J Work Environ Health 2000;26(4):292-298

https://doi.org/10.5271/sjweh.545

Issue date: Aug 2000

Association between plasma testosterone and work-related neck and shoulder disorders among female workers

by Kaergaard A, Hansen ÅM, Rasmussen K, Andersen JH

The following article refers to this text: 2016;42(2):103-124

Key terms: anabolism; biomarker; body mass index; MSD; musculoskeletal disorder; pain; repetitive work; smoking; stress

This article in PubMed: www.ncbi.nlm.nih.gov/pubmed/10994794 


\title{
Association between plasma testosterone and work-related neck and shoulder disorders among female workers
}

\author{
by Anette Kaergaard, MD,' Åse M Hansen, PhD, ${ }^{2}$ Kurt Rasmussen, MD, 'Johan H Andersen, $M D^{\top}$
}

\begin{abstract}
Kaergaard A, Hansen ÅM, Rasmussen K, Andersen JH. Association between plasma testosterone and workrelated neck and shoulder disorders among female workers. Scand J Work Environ Health 2000;26(4):292-298.
\end{abstract}

\begin{abstract}
Objectives The aims were to study the association between anabolic hormone testosterone in plasma and the presence of musculoskeletal disorders among female workers and to study the association between changes in testosterone and changes in musculoskeletal complaints.

Methods In a cross-sectional design 145 women from 2 different industries filled out questionnaires about current musculoskeletal complaints, participated in a clinical examination of the neck and upper extremities, and gave a blood sample for the analysis of free testosterone in plasma. Individual characteristics, psychosocial job factors, and stress reactions were evaluated by questionnaires. In a follow-up study a subgroup of 73 sewing machine operators from the cross-sectional study was reexamined after 1 year.

Results The group of women with clinically verified neck or shoulder disorders had significantly lower plasma testosterone than the women with no disorders. Furthermore, the testosterone level showed a negative association with age and a positive association with smoking and body mass index. Changes in pain status or clinically diagnosed musculoskeletal disorders were not associated with changes in testosterone levels. However, this finding may well be due to a strong plant influence in that marked changes in testosterone levels were observed for 2 of the 3 participating plants.

Conclusions There is some indication of an association between musculoskeletal disorders in the neck and shoulders and a low level of free plasma testosterone. The study failed to clarify the associations found between changes in testosterone and changes in musculoskeletal complaints over time.
\end{abstract}

Key terms anabolism, biomarker, body mass index, musculoskeletal disorders, pain, repetitive work, stress, smoking.

The extent to which individual physiological characteristics are associated with the risk of developing workrelated musculoskeletal disorders has not been well described. The use of biomarkers may be a way of evaluating any predisposition among persons or populations, but no such markers of susceptibility for work-related musculoskeletal disorders have yet been identified (1). The initial occurrence of most work-related musculoskeletal disorders is intermittent, but, after a course of years some develop into more chronic pain syndromes. Therefore, an optimal biomarker would be able to detect a disorder at an early stage and therefore provide a possibility to discuss intervention against progression into a chronic disorder.

It is generally agreed that the risk factors of musculoskeletal disorders are multifactorial and evidently people respond differently to external exposures.
Researchers using a cascade model (exposure, dose, capacity, response) for the pathogenesis of work-related musculoskeletal disorders have been accused of focusing on associations between the top and bottom of the cascade (2). Indeed many epidemiologic studies have been concerned with the relationship between physical work load and musculoskeletal disorders (3-5). Meanwhile, an increasing number of studies have also investigated the possible associations between psychosocial job factors and the development of musculoskeletal pain and disorders $(6-8)$. In these studies stress reactions are either considered to be effects of an external exposure or intermediates between perceived psychosocial strain and the development of musculoskeletal pain.

Several studies have tested the hypothesis that high job strain induces the mobilization of energy and the inhibition of anabolism (9-11). Anabolic hormones,

1 Department of Occupational Medicine, Herning Hospital, Herning, Denmark.

2 National Institute of Occupational Health, Copenhagen, Denmark.

Reprint requests to: Dr Anette Kaergaard, Department of Occupational Medicine, Herning Hospital, Gl Landevej 61, DK7400 Herning, Denmark. [E-mail: hecak@ringamt.dk] 
including testosterone, have been of interest as intermediary stress sensitive hormones that may be associated with the development of musculoskeletal problems. However, the findings have varied $(8,9,12)$, and further investigation is needed.

No identified studies have tried to correlate the levels of free plasma testosterone with work-related musculoskeletal disorders diagnosed by a combination of self-reported complaints and a clinical examination. Nor do we know if free plasma testosterone can be used as a measure of individual susceptibility to the development of a work-related musculoskeletal disorder or if, perhaps, it reflects an already existing disorder. Using both a cross-sectional and a longitudinal design, the present study aimed at testing the following hypotheses: (i) workrelated musculoskeletal disorders are associated with low levels of free plasma testosterone in women and (ii) changes in the levels of free plasma testosterone are negatively associated with changes in musculoskeletal complaints.

\section{Materials and methods}

\section{Design}

The study consisted of a baseline cross-sectional investigation and a follow-up study. For an overall sampling schedule of the study, see figure 1.

\section{Study group}

A random sample of 150 women from 4 different plants were asked to participate in the study. The involved plants and departments were already included in the Danish PRIM (project on research and intervention in monotonous work) health-study cohort (13). Twenty-nine of the 150 women refused to participate and for each of these a new employee was invited to enter the study. A total of 145 women was finally included.

Ninety-seven women came from 3 different textile plants (Sew1, Sew2, Sew3) and were mainly sewing machine operators. Forty-eight women worked in a toy production factory (Toy1) and were either working on an assembly line or had more varied work, including process monitoring. The pay system was payment by the piece for the sewing machine operators and payment by the hour for the toy production workers. Both groups worked only the day shift. The mean age of the subjects $(\mathrm{N}=145)$ at the time of the baseline examination was 40.4 (SD 9.1) years. Only the 97 sewing machine operators were included in the follow-up part of the study (figure 1). Of the 97 sewing machine operators, 24 had dropped out at the time of the follow-up examination, mainly as a result of reduced production and redundancy in the textile industry during this period (10 were laid off owing to a reduction in production, 4 had found another job, 2 had withdrawn from the study, 5 were either fired or had quit for reasons of health, 3 were absent on the day of the blood sampling). The 73 sewing machine operators who participated in both the baseline and follow-up examinations were utilized in the statistical analysis of the follow-up data. Five women pregnant in the 1st trimester were accepted. Women using birth control pills or estrogen would be expected to have a low testosterone level due to their medication. Because we tested low testosterone as a risk factor for musculoskeletal problems in our study, they were included. The exclusion criteria were known rheumatic disorders and diabetes mellitus.

\section{Blood sampling}

All the participants provided blood samples at the worksite on Tuesday mornings between 0900 and 1100 . The 1 st sampling round (R1) took place a few days after the clinical examination and was followed by the 2 nd sampling round (R2) 2 weeks later. After 1 year the sampling schedule was repeated, this time with 4 to 6 weeks between the blood sampling rounds (R3 and R4).

The choice of free versus total testosterone differs among studies and so does the gender composition of study groups. In women testosterone is produced in the adrenal cortex (25\%) and ovaries (25\%) and by transformation $(50 \%)$ in the liver, kidneys, bowel, lungs, adipose tissue, and central nervous system, while in men it is primarily produced in the testicles, a small portion being produced in the adrenal cortex (14). Because of the low concentration of free testosterone in women, analytical measures have mainly been restricted to total testosterone. However, commercial methods for measuring free testosterone are now available. For the determination of free plasma testosterone, a competitive radioimmune assay (Coat-a-count kits), purchased from DPC (Los

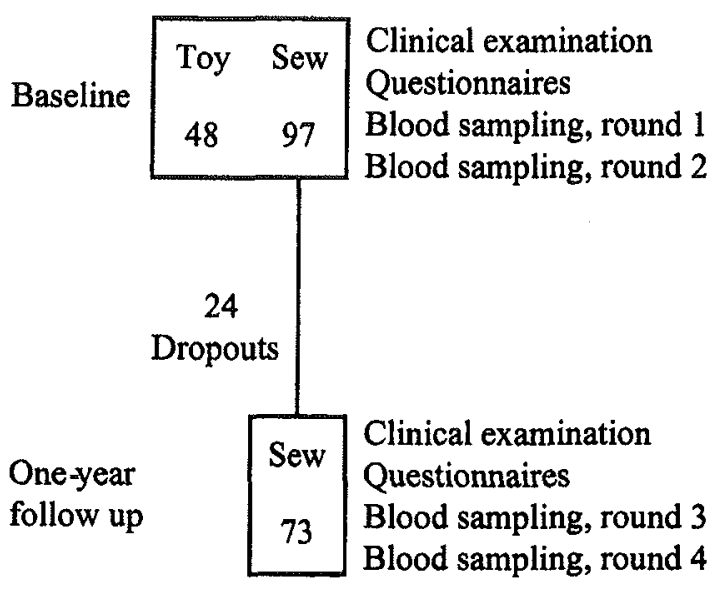

Figure 1. Sampling schedule and data sources for 145 women in the baseline cross-sectional study and for 97 women in the follow-up study. (Toy = toy production workers, Sew $=$ sewing machine operators) 
Angeles, CA, USA), was used. The interassay coefficient of variation of the testosterone level was $17 \%$ at 3.9 pmol/l. To assure the quality of the analyses, commercial matrix reference materials for free testosterone were analyzed together with the samples.

\section{Questionnaires}

Immediately before the clinical examination each person returned a self-administered questionnaire about current musculoskeletal problems in several neck and upper extremity regions. The same set of 4 questions was asked for each region. The questions were answered by an indication on a 10-point scale ranging from 0 to 9 . In this study we used a summation of scores from the following 3 regions: neck, right shoulder, left shoulder (maximum score 108) (Cronbach's alpha 0.93). The questionnaire was a modified form of the grading method used for chronic pain severity by Von Korff et al (15), the questions intending to combine pain intensity and restriction in daily activity over a 3-month period. The examiners were blinded as to the answers to the questionnaire.

At the time of the baseline examination the participants also completed a questionnaire including 23 items from the Karasek job-characteristic scale (16) and 8 items on job satisfaction. The answer to each item was dichotomized and given a raw score of 1 or 0 , and 4 scales were constructed as raw score summations: job demand $(0-$ 3) (Cronbach's alpha 0.53), job control $(0-14)$ (Cronbach's alpha 0.72), social support $(0-6)$ (Cronbach's alpha 0.53 ), and job satisfaction $(0-8)$ (Cronbach's alpha 0.80 ). After 1 year the job characteristic scales were reduced due to the construction of a less comprehensive PRIM questionnaire for repeated measurements in the follow-up studies. A job-strain score was constructed by multiplying the demand ( 2 items, high demand $=$ high score) and control (5 items, low control = high score) scores, giving a possible score of 10 to 160 .

On each day of the 4 blood sampling rounds all the participants answered a series of questions on personal characteristics and individual habits and also responded to 21 items from the stress profile questionnaire developed by Setterlind (17). The answer to each item was dichotomized and divided into the following 3 scales: behavioral stress reactions $(0-9)$ (Cronbach's alpha $0.69)$, emotional stress reactions $(0-8)$ (Cronbach's alpha 0.70$)$, and cognitive stress reactions $(0-4)$ (Cronbach's alpha $=0.58$ ). In the baseline examination a scale was added to the questionnaire on psychosomatic symptoms (0-6) (Cronbach's alpha 0.19). Because the scales showed a very low variation, changes in stress level were evaluated by a stress index, constructed as a summation of scores $(0-4)$ from each of the 21 items (possible score 0 -84). The questions concerning quality of sleep, smoking habits, and consumption of alcohol and coffee all inquired about use on the day before the blood sampling.

\section{Clinical examination}

The neck and shoulder examination focused on palpation tenderness, active range of motion in the neck and shoulders, and tests for impingement pain, and pain on resisted abduction in the shoulder. No diagnoses were made during the examination. The outcome variables were cervical syndrome (positive foramen compression test or reduced range of movements in 2 of 4 directions), rotator-cuff tendinitis (palpation tenderness at the tuberculum major humeri and sign of subacromial impingement), and myofascial pain syndrome (palpation tenderness graded 2 or 3 ( 0 to 3 scale) for either or both the upperneck muscle (semispinalis capitis) and the upper trapezius muscle and for either or both the supraspinatus muscle and the infraspinatus muscle, the outcome being combined from results on self-reported pain and clinical findings. Detailed descriptions of the questionnaire, clinical examination, and diagnostic criteria have been submitted for publication.

From the clinical examination we have chosen to include only neck or shoulder disorders and self-reported complaints from the same regions. We know from earlier studies (18) that these disorders are highly prevalent among sewing machine operators and often have a pronounced effect on disability. In this study, neck or shoulder disorders comprised $88 \%$ of all the disorders in the neck and upper-extremity region.

\section{Analysis and statistics}

Associations between hormone levels were analyzed with a Pearson 2-tailed correlation. The means of the 2 groups were compared in independent t-tests, and the means of 2 variables for 1 group were compared using the paired sample t-test. Simple linear and multiple regressions were applied to study the relationship between testosterone and several explanatory variables. Statistical significance was defined as $P<0.05$. The statistical analyses were performed using the SPSS (Statistical Package for the Social Sciences).

\section{Results}

The mean level of free testosterone in the 4 sampling rounds is shown in table 1 . The correlation coefficient (r) between testosterone in round 1 and round 2 was high $(\mathrm{r}=0.72, \mathrm{P}<0.001)$. In spite of 5 weeks between sampling rounds 3 and 4 we still found a high correlation between testosterone in the 2 rounds $(\mathrm{r}=0.62, \mathrm{P}<0.001)$ Thus, for each subject, we decided to operate with only 1 value for the baseline (mean of rounds 1 and 2) and 1 value for the 1-year follow-up (mean of rounds 3 and 4).

The group distribution is given in table 2 for several personal characteristics derived from the 
Table 1. Mean free testosterone level in the baseline examination (R1 and R2) and after 1 year of follow-up (R3 and R4). (R1-R4 = sampling rounds 1 to 4 ; Sew = sewing machine operators, Toy = toy production workers )

\begin{tabular}{|c|c|c|c|c|c|}
\hline \multirow[t]{2}{*}{ Round } & \multirow{2}{*}{$\begin{array}{c}\text { Number } \\
\text { of } \\
\text { workers }\end{array}$} & \multicolumn{4}{|c|}{ Testosterone $(\mathrm{pmol} / \mathrm{l})$} \\
\hline & & Mean & SD & Range & Median \\
\hline \multicolumn{6}{|l|}{ R1 } \\
\hline Sew & 92 & 3.4 & 2.1 & $0.1-10.6$ & 2.9 \\
\hline $\mathrm{R} 2^{\text {Toy }}$ & 44 & 5.2 & 2.5 & $1.2-11.7$ & \\
\hline new & \multicolumn{4}{|c|}{ R2 } & \\
\hline Toy & 44 & 4.0 & 1.9 & $1.2-10.1$ & 3.1 \\
\hline R3 & & & & & \\
\hline Sew & 77 & 2.7 & 1.9 & $0.1-10.3$ & 2.3 \\
\hline Sew & 79 & 3.0 & 2.0 & $0.2-9.0$ & 2.8 \\
\hline
\end{tabular}

self-administered questionnaires and from the clinical examination, together with the unadjusted mean testosterone values. Data on hypertension, current infections, use of medication, alcohol and coffee consumption, and sleep quality are not reported because they showed no association with the level of testosterone.

\section{Cross-sectional associations}

In the bivariate analyses significant negative associations were found between testosterone and age, neck or shoulder disorders, use of oral contraceptives or estrogen, and work as a sewing machine operator. Significant positive associations were found between testosterone and body mass index (BMI) and smoking (table 3). In the multiple linear regression model the effect of workgroup disappeared. This effect was explained primarily by an unequal distribution of BMI and smoking habits in the 2 groups. All the other covariates contributed to the model with only small changes in estimates (table 3 ).

Table 4 shows the baseline distribution of self-reported job demand, job control, social support, and job satisfaction among sewing machine operators and toy production workers. Job strain, which implies a multiplicative effect of demand and control, was not found to correlate with the testosterone level when tested in a multiple linear regression model controlling for age, BMI, oral contraceptives or estrogen, smoking, and neck or shoulder disorders $(\mathrm{B}=0.006, \mathrm{t}=0.101, \mathrm{P}=0.919)$.

Scores from the Setterlind stress profile scales showed a very low variation with about $90 \%$ of all subjects scoring 0 or 1 on the respective scales. Neither the separate scales nor a combining stress index (mean 10.7, median 7.00, SD 12.24, range 0-67) were associated with the level of testosterone.

\section{Follow-up results}

In the 1-year follow-up the mean testosterone value showed a significant decrease for the whole group of 73 women who participated in both the baseline and
Table 2. Baseline description of the study group ( $N=145)$, including the unadjusted mean values of free testosterone in defined subgroups. $(B M I=$ body mass index, Sew $=$ sewing machine operators, Toy = toy production workers)

\begin{tabular}{|c|c|c|c|c|}
\hline \multirow[t]{2}{*}{ Characteristic } & \multicolumn{2}{|c|}{ Workers } & \multicolumn{2}{|c|}{ Testosterone (pmol/l) } \\
\hline & $N$ & $\% a$ & Mean & $\mathrm{SD}$ \\
\hline \multicolumn{5}{|l|}{ Age (years) } \\
\hline$<35$ & 39 & 26.8 & 4.3 & 2.7 \\
\hline $35-44$ & 53 & 36.6 & 4.0 & 2.1 \\
\hline$\geq 45$ & 53 & 36.6 & 3.2 & 1.9 \\
\hline \multicolumn{5}{|l|}{$\mathrm{BMI}\left(\mathrm{kg} / \mathrm{m}^{2}\right)$} \\
\hline$<20$ & 14 & 9.7 & 2.6 & 0.9 \\
\hline $20-25$ & 66 & 45.6 & 3.4 & 2.1 \\
\hline $25-30$ & 43 & 29.7 & 3.8 & 2.2 \\
\hline$\geq 30$ & 21 & 14.5 & 5.6 & 2.4 \\
\hline \multicolumn{5}{|l|}{ Workgroup } \\
\hline Sew & 97 & 66.9 & 3.4 & 2.2 \\
\hline Toy & 48 & 33.1 & 4.5 & 2.1 \\
\hline \multicolumn{5}{|c|}{ Oral contraceptives or estrogen } \\
\hline Yes & 25 & 17.2 & 2.4 & 2.1 \\
\hline No & 113 & 77.9 & 4.1 & 1.4 \\
\hline \multicolumn{5}{|l|}{ Smoking } \\
\hline No & 70 & 48.3 & 3.2 & 1.9 \\
\hline$<15$ cigarettes per day & 40 & 27.6 & 4.0 & 2.2 \\
\hline$\geq 15$ cigarettes per day & 35 & 24.1 & 4.8 & 2.6 \\
\hline \multicolumn{5}{|l|}{ Pain } \\
\hline Score 0 & 38 & 26.2 & 4.3 & 2.4 \\
\hline Score $1-11$ & 39 & 26.9 & 4.1 & 2.2 \\
\hline Score $12-23$ & 26 & 17.9 & 3.5 & 2.0 \\
\hline Score $\geq 24$ & 42 & 29.0 & 3.2 & 2.1 \\
\hline \multicolumn{5}{|l|}{ Neck or shoulder disorder } \\
\hline Yes & 32 & 22.1 & 2.8 & 1.5 \\
\hline No & 112 & 77.2 & 4.0 & 2.3 \\
\hline
\end{tabular}

a Percentage of total number of workers.

Table 3. Effect of individual characteristics, workgroup, and neck or shoulder disorder on the baseline plasma testosterone level in simple linear and multiple regression analyses. $(B=$ regression coefficient)

\begin{tabular}{|c|c|c|c|c|c|c|}
\hline \multirow[t]{2}{*}{ Covariates } & \multicolumn{3}{|c|}{$\begin{array}{l}\text { Testosterone } \\
\text { (unadjusted) }\end{array}$} & \multicolumn{3}{|c|}{$\begin{array}{l}\text { Testosterone } \\
\text { (adjusteda) }\end{array}$} \\
\hline & $B$ & $t$-Value & P-value & B & t-Value & P-value \\
\hline Age & -0.04 & -2.09 & 0.038 & -0.06 & -3.68 & $<0.001$ \\
\hline Body mass index & 0.17 & 4.30 & $<0.001$ & 0.18 & 5.68 & $<0.001$ \\
\hline Workgroup ${ }^{b}$ & -1.04 & -2.70 & 0.008 & -0.29 & -0.95 & 0.346 \\
\hline \multicolumn{7}{|l|}{ Oral contraceptives } \\
\hline or estrogenc & -1.70 & -3.80 & $<0.001$ & -2.03 & -5.32 & $<0.001$ \\
\hline Smoking ${ }^{d}$ & 1.20 & 3.35 & 0.001 & 1.25 & 4.34 & $<0.001$ \\
\hline $\begin{array}{l}\text { Neck or shoulder } \\
\text { disorder }\end{array}$ & -1.26 & -2.95 & 0.004 & -1.00 & -2.86 & 0.005 \\
\hline
\end{tabular}

a Adjusted = all covariates were entered into the regression model at the same time.

b Workgroup = 1 if sewing machine operator, 0 if toy production worker.

c Oral contraceptives or estrogen $=1$ if yes, 0 if no.

a Smoking $=1$ if yes, 0 if no.

e Neck or shoulder disorder $=1$ if yes, 0 if no.

follow-up examinations, but when separated by textile plant, this result was modified as shown in table 5 .

The significant increase in the mean testosterone level of the workers in the Sew1 plant and the significant 
Table 4. Baseline distribution of the work-related self-reported psychosocial factors for the sewing machine operators (Sew) $(\mathrm{N}=97)$ and the toy production workers (Toy) $(\mathrm{N}=48)$ and the crude mean testosterone values according to these factors.

\begin{tabular}{|c|c|c|c|c|}
\hline \multirow[t]{2}{*}{ Scales } & \multirow[t]{2}{*}{ Sew $(\%)$} & \multirow[t]{2}{*}{ Toy (\%) } & \multicolumn{2}{|c|}{ Testosterone } \\
\hline & & & $\begin{array}{c}\text { Mean } \\
(\mathrm{pmol} / \mathrm{l})\end{array}$ & SD \\
\hline \multicolumn{5}{|l|}{ Job demand } \\
\hline 0 (low) & 1 & 39 & 3.5 & 1.5 \\
\hline 1 & 22 & 15 & 4.0 & 2.1 \\
\hline 2 & 39 & 17 & 3.9 & 2.6 \\
\hline 3 (high) & 38 & 29 & 3.7 & 2.2 \\
\hline \multicolumn{5}{|l|}{ Job control } \\
\hline $0-4$ (high) & 11 & 31 & 4.5 & 1.8 \\
\hline $5-9$ & 62 & 46 & 3.7 & 2.3 \\
\hline $10-14$ (low) & 27 & 23 & 3.8 & 2.3 \\
\hline \multicolumn{5}{|l|}{ Social support } \\
\hline $0-1$ (high) & 79 & 63 & 3.7 & 2.2 \\
\hline $2-4$ & 30 & 31 & 3.8 & 2.0 \\
\hline $5-6(10 w)$ & 1 & 6 & 6.5 & 3.0 \\
\hline \multicolumn{5}{|l|}{ Job satisfaction ${ }^{a}$} \\
\hline $0-2$ (high) & 86 & 83 & 4.0 & 2.0 \\
\hline $3-5$ & 8 & 15 & 4.2 & 2.5 \\
\hline $6-8$ (low) & 6 & 2 & 3.2 & 2.8 \\
\hline
\end{tabular}

a The job satisfaction scale was completed by 79 sewing machine operators only.

decrease in the Sew 2 plant was based on an increased testosterone value among 13 of the 15 subjects in the Sew1 plant and a decreased testosterone value among 33 of the 38 subjects in the Sew 2 plant.

Changes in the testosterone level from the baseline to the 1-year follow-up revealed no significant correlation with changes in the pain score or changes in the stress index during the same period (table 5). Some indication of a negative association with changes in job strain was seen. Thirteen persons equally distributed between the 3 plants had either gained $(\mathrm{N}=6)$ or lost $(\mathrm{N}=7)$ a diagnosis at the time of the follow-up. Meanwhile, the general changes among the workers in the Sew1 and Sew2 plants appeared to overshadow any expected testosterone changes due to changes in pain status or neck or shoulder disorders.

At the 1-year follow-up we repeated the cross-sectional analyses $(\mathrm{N}=73)$ and no longer found testosterone level to be associated with the pain score or neck or shoulder disorders (16 cases). However, had the baseline analyses included these 73 subjects only, the adjusted association between neck or shoulder disorders and testosterone would not have been significant $(B=-0.73, t-$ value $=-1.55, P$-value $=0.125$ ), as seen when all of the 145 subjects were analyzed (table 3 ). The associations of testosterone with BMI, oral contraceptives or estrogen, and smoking were found again, but the association with age had disappeared. There were no changes in the frequencies of smoking or the use of oral contraceptives or estrogen from the baseline to the time of follow-up. The stress index and job strain were still not associated with testosterone level.

\section{Discussion}

This baseline cross-sectional study showed a negative association between the free plasma testosterone and

Table 5. Mean values for testosterone, the pain score, job strain, and the stress index in the baseline examination and after 1 year of follow-up for the whole study group ( $N=73$ ) and for subgroups by plant. (Sew1, Sew2, Sew3 = 3 different textile plants, $r=$ correlation coefficient)

\begin{tabular}{|c|c|c|c|c|c|c|c|c|}
\hline \multirow[t]{2}{*}{ Group } & \multicolumn{2}{|c|}{ Testosterone $(\mathrm{pmol} / \mathrm{l})$} & \multicolumn{2}{|c|}{ Pain score ${ }^{a}$} & \multicolumn{2}{|c|}{ Job strain ${ }^{b}$} & \multicolumn{2}{|c|}{ Stress index ${ }^{c}$} \\
\hline & Mean & SD & Mean & SD & Mean & SD & Mean & SD \\
\hline \multicolumn{9}{|l|}{ Whole group $(\mathrm{N}=73)^{\mathrm{d}}$} \\
\hline Baseline & 3.25 & 2.04 & 20.2 & 21.2 & 72.6 & 21.4 & 10.7 & 13.9 \\
\hline One-year follow up & 2.77 & 1.76 & 22.0 & 20.5 & 72.9 & 21.1 & 11.4 & 11.9 \\
\hline P-value & \multicolumn{2}{|c|}{0.021} & \multicolumn{2}{|c|}{0.310} & \multicolumn{2}{|c|}{0.910} & \multicolumn{2}{|c|}{0.659} \\
\hline \multicolumn{9}{|l|}{ Sew1 $(N=15)$} \\
\hline Baseline & 1.99 & 1.57 & 27.3 & 21.1 & 78.2 & 24.6 & 11.4 & 18.4 \\
\hline One-year follow up & 3.13 & 1.87 & 28.1 & 21.7 & 83.1 & 22.8 & 10.2 & 7.9 \\
\hline P-value & \multicolumn{2}{|c|}{0.019} & \multicolumn{2}{|c|}{0.877} & \multicolumn{2}{|c|}{0.348} & \multicolumn{2}{|c|}{0.757} \\
\hline \multicolumn{9}{|l|}{ Sew2 $(N=38)$} \\
\hline Baseline & 3.92 & 2.15 & 16.2 & 21.6 & 68.2 & 18.4 & 6.8 & 7.6 \\
\hline One-year follow up & 2.69 & 1.76 & 16.3 & 17.6 & 73.8 & 21.3 & 9.0 & 8.1 \\
\hline P-value & \multicolumn{2}{|c|}{0.000} & \multicolumn{2}{|c|}{0.984} & \multicolumn{2}{|c|}{0.107} & \multicolumn{2}{|c|}{0.096} \\
\hline \multicolumn{9}{|l|}{ Sew3 $(N=20)$} \\
\hline Baseline & 2.92 & 1.63 & 22.3 & 19.8 & 77.8 & 23.6 & 18.9 & 17.6 \\
\hline One-year follow up & 2.65 & 1.71 & 28.5 & 22.4 & 61.2 & 13.2 & 17.8 & 18.3 \\
\hline P-value & \multicolumn{2}{|c|}{0.311} & \multicolumn{2}{|c|}{0.027} & \multicolumn{2}{|c|}{0.008} & \multicolumn{2}{|c|}{0.828} \\
\hline
\end{tabular}

a Pain score $0-108$. Job strain 10-160. Stress index 0-84.

d Correlation between changes in testosterone (follow-up value minus baseline value) and changes in the pain score $(r=0.074, P$-value 0.537$)$, changes in job strain $(r=-0.219, P$-value 0.080$)$, and changes in the stress index $(r=0.031, P$-value 0.811$)$. 
work-related neck or shoulder disorders in female workers. However, the cross-sectional analyses at the time of the follow-up failed to support the baseline results. The follow-up analysis showed no association between changes in testosterone level and changes in musculoskeletal complaints.

One of the main hypotheses behind our study was that a low testosterone level, being a psychophysiological stress response, may affect the musculoskeletal repair process and therefore be an indicator of early change in the process of chronic musculoskeletal disorders. In a suggestive case report from Belgium (19), a young sportsman with abnormally low testosterone suffered from chronic problems with muscle strain. After treatment with antiestrogen, his testosterone concentration normalized, his well-being improved, and there was a spectacular decrease in his muscle injury rate during the following 6 months. A recent study (8) of 116 workers who worked with visual display units supports the hypothesis of an association between a low concentration of the anabolic hormone testosterone and the intensity of musculoskeletal symptoms.

Our baseline cross-sectional study supports these results with a finding of a negative association between free plasma testosterone and verified work-related neck or shoulder disorders and musculoskeletal complaints after control for important confounders. A strong positive association between testosterone and BMI and smoking recur in all the analyses. Other comparable studies fail to report on these associations (9-12), but similar findings have been indicated previously (20).

Our results only provided a slight indication of an association between job strain and testosterone level. The same uncertainty of an association was seen in other studies. For example, Theorell et al (9) found an increase in total testosterone when job strain diminished, but only in sedentary workgroups (men) with low physical activity. In a subsequent study by Theorell et al (12), testosterone was observed to increase with self-reported muscle tension and several negative psychosocial work conditions. The author had no explanation for the differences in these results. Our study was based on the measurement of free testosterone, which is the biologically active fraction of testosterone. As the free fraction may be more sensitive to, for example, acute change in mood or physical activity, total testosterone could have been a relevant complementary measure. However, the 2 workgroups in this study would be equally classified with regard to physical activity, and the data on, for example, hypertension, alcohol consumption, and sleep quality showed no association with the testosterone values.

In our study stress responses were measured by the Setterlind stress profile questionnaire (17), which unfortunately possessed no discriminative ability within the groups. One possible explanation could be that the participants did not feel stressful. More likely, the stress scales were not sensitive to the presence or changes in nonacute stress situations. From regular plant visits and from interviews of the participants, we knew that the ongoing job reorganization and elimination of certain jobs were affecting the employees, but this effect was not reflected in the answers to the Setterlind questions.

Twenty-nine of the PRIM study subjects were not willing to participate in the biomarker study (13). They were equally distributed between the 4 plants, and the main reason given was fear of the blood sampling procedure. The dropout of 24 sewing machine operators was mainly caused by the elimination of certain jobs and the shift of textile production to eastern Europe during this period. They represented the same distribution of neck or shoulder disorders and testosterone levels as the remaining group.

We found a very high prevalence of smokers in this study. While $35 \%$ of the adult female population in Denmark smokes, $51.4 \%$ of the women in this study were smokers, with a prevalence as high as $64.4 \%$ among the toy production workers. We have no other explanations but social factors and perhaps a specific work-related culture for these differences. We also found a high prevalence $(42.2 \%)$ of women with a BMI higher than 25 , compared with an average of $28 \%$ in the general Danish female population.

At the time of the follow-up we found significant changes in the free testosterone level (table 4), and these changes were not related to changes in the pain scores or the occurrence of musculoskeletal disorders. At the same time the cross-sectional association between testosterone and these variables disappeared. The changes were not due to changes in BMI, smoking habits, or the use of oral contraceptives or estrogen. Furthermore, the blood samples were drawn in the same month and on the same weekday to eliminate the possibility of seasonal variation and the effect of tiredness, which can vary according to the day of the week. Many other unrecorded factors outside the job may have differed between and within the subjects at different times. However, this possibility does not explain why the testosterone levels of almost all the subjects within the Sew 1 and Sew2 plants changed in the same direction. An analytical error seems unlikely in that laboratory analyses were continuously evaluated by participation in an external quality assessment program, in which reference materials were analyzed together with the study samples. No deviations were found.

At the time of the follow-up we had indications in notes (written on the day of the blood sampling) that the employees in the Sew 2 plant were working under very high pressure, compared with the circumstances of the baseline measurements. [Citation: "The department seems tremendously busy. Many employees work extra hours on Saturdays. The impression of the atmosphere 
in the department is different from the 2 nd rounds. People rush and everybody talks about how busy they are."]

At the time of the follow-up the following conclusions were reached after the interview at the Sewl plant: "They seldom experience stress like they did when they started to work in the production groups"; "the group has come far when it comes to taking on responsibility in daily planning and coordination of the work". Thus, in this situation, we had some incomplete qualitative data corresponding to our own impression of stress level among the sewing machine operators. If these observations reflected the actual stress level, the values would have corresponded with the observed changes in testosterone in the Sew1 and Sew2 plants. Together with a strongly reduced study group, the lack of association between testosterone and musculoskeletal complaints and disorders may be explained by some of the these conditions.

It must be highly emphasized that no systematic qualitative analysis was performed, and the aforementioned considerations could be purely speculative. However, they could support some new developments in research on how one should study stress and work organizational changes in the workplace. The questionnaire in this study, developed for between-plant and group comparisons, may be too general in nature and partly invalid as a measure of exposure.

In conclusion, our study partially confirms the hypothesis of an association between work-related musculoskeletal disorders and low levels of plasma testosterone. However, these findings suggest the need to perform additional studies on female workers.

\section{Acknowledgments}

This project was supported by grants from The Danish Working Environment Found and The Danish Research Academy.

\section{References}

1. Mastin JP, Henningsen GM, Fine LJ. Biomarkers of musculoskeletal disorders. In: Schulte PA, Perera FR, editors. Molecular epidemiology: principles and practices. San Diego (CA): Academic Press Inc, 1993.

2. Armstrong TJ, Buckle P, Fine LJ, Hagberg M, Jonsson B, Kilbom $\AA$, et al. A conceptual model for work-related neck and upper-limb musculoskeletal disorders [review]. Scand J Work Environ Health 1993;19:73-84.

3. Hagberg M, Silverstein B, Wells R, Smith MJ, Hendrick HW, Carayon P, et al. In: Kuorinka I, Forcier L, editors. Work related musculoskeletal disorders (WMSDs): a reference book for prevention. London: Taylor \& Francis. 1995:17-137.

4. Ohlsson K, Attewell RG, P lsson B, Karlsson B, Balogh I, Johnsson B, et al. Repetitive industrial work and neck and upper limb disorders in female. Am J Ind Med 1995;27:731— 47.

5. Bernard BP, editor. Musculoskeletal disorders and workplace factors: a critical review of epidemiologic evidence for workrelated musculoskeletal disorders of the neck, upper extremity, and low back. Cincinnati $(\mathrm{OH})$ : National Institute for Occupational Safety and Health (NIOSH), 1998. Publication, no 97-141.

6. Bongers PM, Winter de CR, Kompier MAJ, Hildebrandt VH. Psychosocial factors at work and musculoskeletal disease [review]. Scand J Work Environ Health 1993;19:297-312.

7. Houtman ILD, Bongers PM, Smulders PGW, Kompier MAJ. Psychosocial stressors at work and musculoskeletal disorders. Scand J Work Environ Health 1994;20:139-45.

8. Wiholm C, Arnetz BG. Musculoskeletal symptoms and headaches in VDU users - a psychophysiological study. Work Stress 1997;11:239—50.

9. Theorell T, Karasek RA, Eneroth P. Job strain variations in relation to plasma testosterone fluctuations in working men — a longitudinal study. J Intern Med 1990;227:31-36.

10. Berg M, Arnetz BB, Lidén S, Eneroth P, Kallner A. TechnoStress. A psychophysiological study of employees with VDUassociated skin complaints. J Occup Environ Med 1992; 34:698-701.

11. Arnetz BB. Techno-stress; a prospective psychophysiological study of the impact of a controlled stress-reduction program in advanced telecommunication system design work. J Occup Environ Med 1996;38:53-65.

12. Theorell T, Harms-Ringdahl K, Ahlberg-Hultén G, Westin B. Psychosocial job factors and symptoms from the locomotor system - a multicausal analysis. Scand J Rehabil Med 1991;23:165-73.

13. Andersen JH, Kaergaard A, Rasmussen K, Frost P, Overgaard E, Bælum J, et al. Myofascial pain and rotator cuff tendinitis among 2400 workers in the Danish PRIM-study, part I [book of abstracts]. Stockholm: International Commission on Occupational Health, 1996:268.

14. Brody S. Obstetrik. Gynekologi [Obstetrics. Gynaecology.]. Stockholm: Nordstedts Förlag, 1987.

15. Von Korff M, Ormel J, Keefe FJ, Dworkin SF. Grading the severity of chronic pain. Pain 1992;50:133 - 49 .

16. Karasek R, Theorell T. Healthy Work, stress, productivity and the reconstruction of working life. New York (NY): Basic Books Inc, 1990.

17. Setterlind S, Larsson G. The stress profile: a psychosocial approach to measuring stress. Stress Med 1995;11:85-92.

18. Andersen JH, Gaardboe O. Prevalence of persistent neck and upper limb pain in a historical cohort of sewing machine operators. Am J Ind Med 1993;24:677—87.

19. Naessens G, Slypere De JP, Dijs H, Driessens M. Hypogonadism as a cause of recurrent muscle injury in a high level soccer player. Int J Sports Med 1995;16:413-7.

20. Haffner SM, Newcomb PA, Marcus PM, Klein BEK, Klein R. Relation of sex hormones and dehydroepiandrosterone sulfate (DHEA-SO ${ }_{4}$ ) to cardiovascular risk factors in postmenopausal women. Am J Epidemiol 1995;142:925-34.

Received for publication: 2 March 1999 